\title{
Submucosal Tunneling Muscle Biopsy for Esophageal Motility Disorders: A Case Report
}

\author{
Aleksandr A. Smirnov, Maya M. Kiriltseva, Aleksandr N. Burakov, Maksim V. Maksimov, Anna V. Botina, Marina M. Saadulaeva \\ and Nadezda V. Konkina
}

Department of Endoscopy, First Pavlov Saint-Petersburg Medical State University, Saint Petersburg, Russia

Submucosal tunneling endoscopic technique can be useful in obtaining esophageal muscle specimens in patients with esophageal motility disorders. Here, we describe the case of a patient with systemic sclerosis. Histological verification of the esophageal involvement in the pathological process was required for the treatment. There were no intra- and post- operational complications. Clin Endosc 2020; 53:370-373

Key Words: Esophagus; Motility disorders; Systemic sclerosis; Tunneling biopsy

\section{INTRODUCTION}

Currently, endoscopic procedures with submucosal tunnel forming are widespread, including peroral endoscopic myotomy (POEM), submucosal tunneling endoscopic resection (STER), and tunneling biopsy of submucosal tumors of the gastrointestinal tract. ${ }^{1}$ This technique can also be applied to access the muscular layer and myenteric plexus of the esophagus for pathological verification in patients with esophageal motility disorders.

The most precise assessment method for obtaining the myenteric plexus and muscular layer specimens is a full-thickness biopsy. The concept and indications of this method are described in the guidelines for histological techniques and reporting, on behalf of the Gastro 2009 International Working Group. 2

Received: June 4, 2019 Revised: July 9, 2019

Accepted: July 22, 2019

Correspondence: Aleksandr N Burakov

Department of Endoscopy, First Pavlov Saint-Petersburg Medical State University, Marshala Novikova St 15/2, Saint Petersburg 197349, Russia

Tel: +7-981-861-02-74, Fax: +7-812-338-66-02, E-mail: Aleksandr.medox@yandex.ru

ORCID: https://orcid.org/0000-0002-6530-9127

(cc) This is an Open Access article distributed under the terms of the Creative Commons Attribution Non-Commercial License (http://creativecommons.org/ licenses/by-nc/3.0) which permits unrestricted non-commercial use, distribution, and reproduction in any medium, provided the original work is properly cited.
In our case, we describe tunneling biopsy of the muscular layer in a patient with systemic sclerosis (SS) for the histological verification of the esophageal involvement in SS.

\section{CASE REPORT}

In 2011, a 48-year-old woman had multiple newly found calcifications in the skin of the back, hips, and shoulders. For the next 5 years, they remained stable; however, in 2015, signs of Raynaud syndrome appeared. At the same time, firm plaques of the skin were revealed.

In March 2016, the clinical picture worsened with the appearance of edema of the fingers ("puffy fingers"). Moreover, skin calcifications were confirmed by radiography. Summarizing all the symptoms mentioned, it was concluded that the patient had CREST syndrome, and treatment with systemic prostaglandins, bisphosphonates, and D-penicillamine was started.

After a 2-year treatment, the calcifications became smaller but Raynaud syndrome remained stable; therefore, bosentan was prescribed.

In November 2018, the patient visited our hospital with complaints of dysphagia. High-resolution esophageal manometry was performed. In the main test, in $100 \%$ of swallows, no esophageal contractions were detected (Fig. 1A). The inte- 
grated relaxation pressure was normal. CCv3.0 classified such results as major disorders of peristalsis, in particular, absent contractility. ${ }^{3}$ During a multiple rapid swallow test, esophageal contractions were not detected (Fig. 1B). In addition, in the beginning of the procedure and after the main test, we measured esophagogastric junction contractile integral (EGJCI) to assess the barrier function of the EGJ. In both cases, the EGJ-CI was null, indicating significant hypotension of the EGJ, decreased barrier function, and increased risk of pathological reflux. ${ }^{4}$
After 2 days, a submucosal tunneling muscle biopsy was performed:

Twenty-five centimeters from the incisors on the posterior wall with $\mathrm{CO}_{2}$ insufflation, a $1.3-\mathrm{cm}$ initial mucosal incision was made. After the submucosal injection, only slight elevation of the mucosa was detected. After forming the short submucosal tunnel, full-thickness resection of the muscular layer (1.0-cm diameter) was performed using an electrosurgical knife. When a specimen was separated from the underlying tissue, it was evacuated using an endoscopic loop. Initial mu-
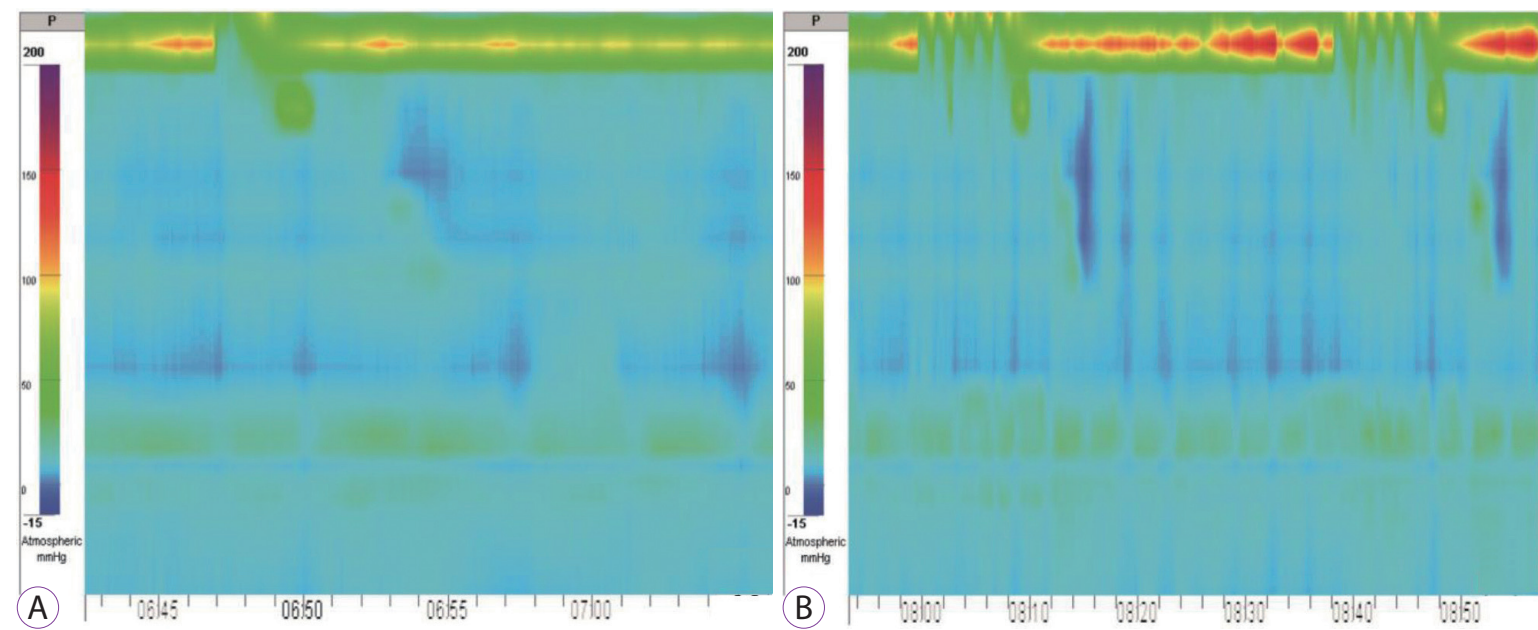

Fig. 1. High-resolution esophageal manometry. (A) Wet swallow $(5 \mathrm{~mL})$ : no esophageal contractions. (B) Multiple rapid swallow test: no esophageal contractions.
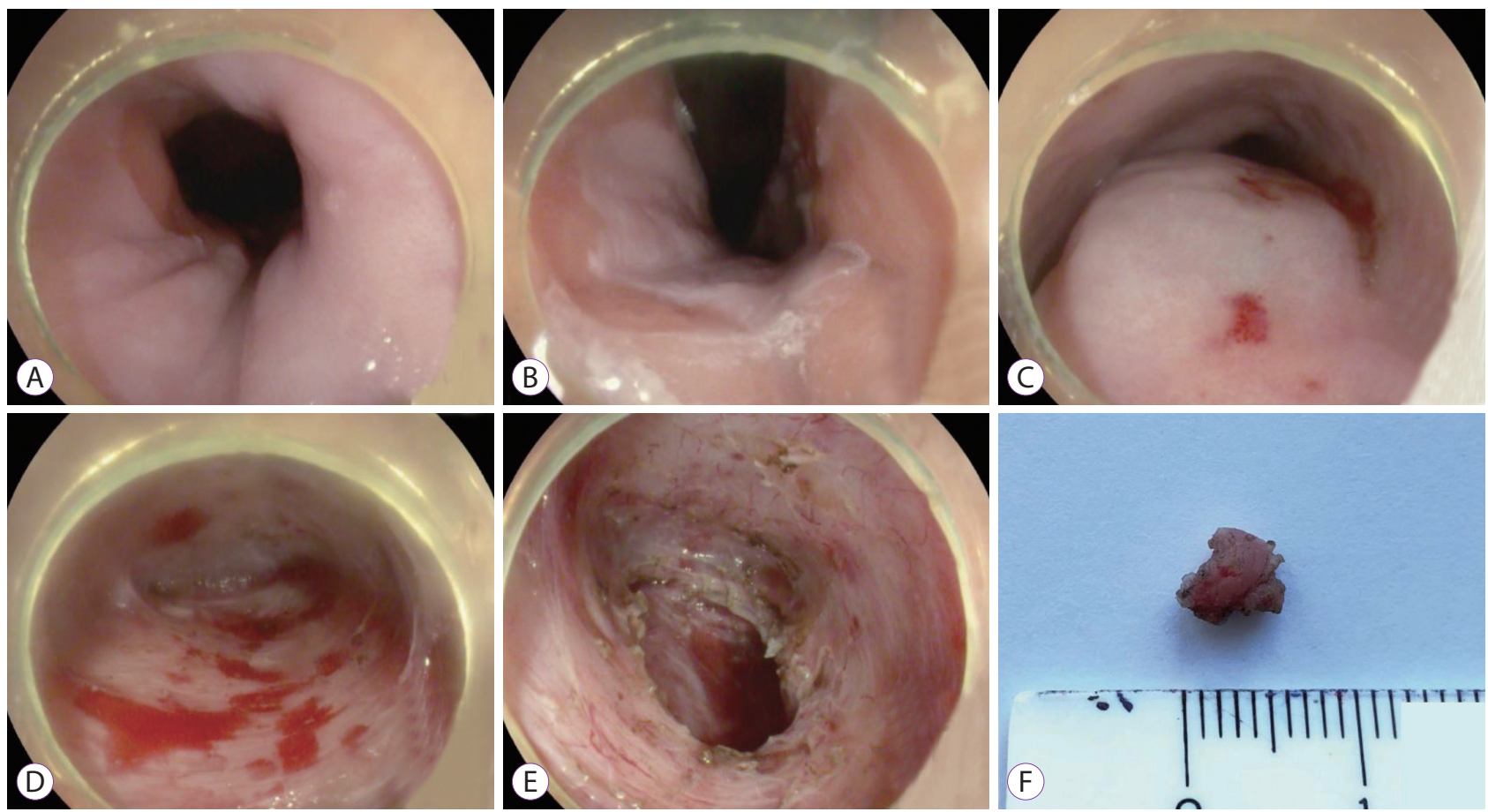

Fig. 2. Steps of the tunneling muscle biopsy. (A) Esophagogastric junction from the lower part of the esophagus. (B) Esophagogastric junction from the stomach. (C) Submucosal injection. (D) Submucosal tunnel. (E) Place of the resected specimen. (F) Resected specimen. 


\section{C clunical enooscopy}

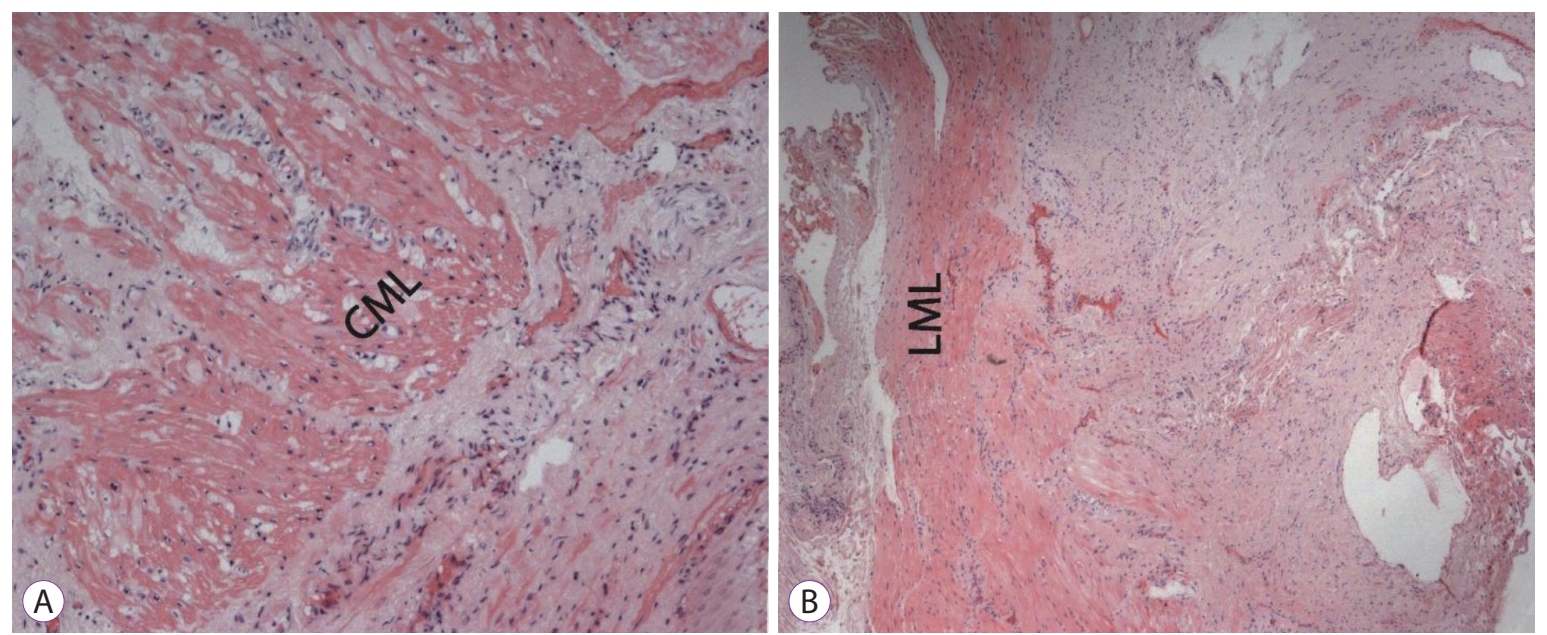

Fig. 3. (A) Atrophy and sclerosis of the circular muscular layer (hematoxylin and eosin, $\times 200$ ). (B) Atrophy and sclerosis of the longitudinal muscular layer (hematoxylin and eosin, $\times 40$ ). CML, circular muscular layer; LML, longitudinal muscle layer.
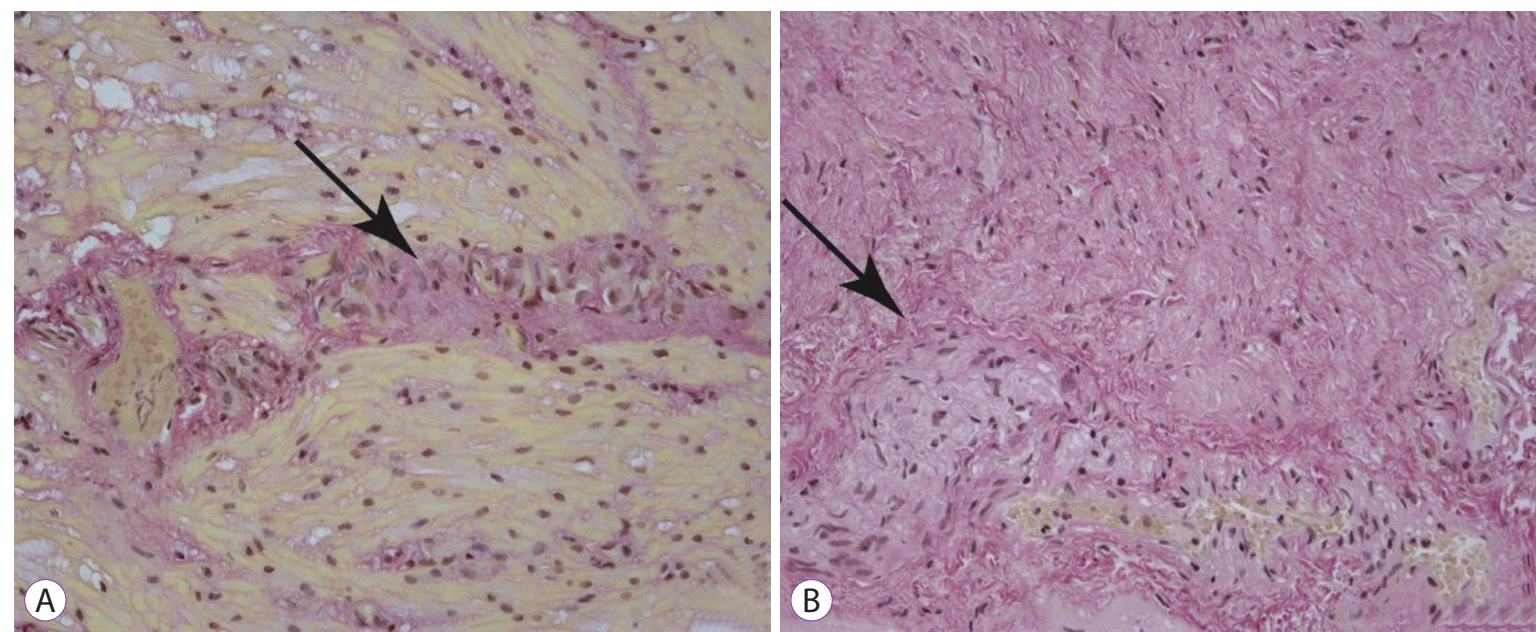

Fig. 4. (A) Perivascular sclerosis; (B) perineural sclerosis (Van Gieson's stain, $\times 200$ ).
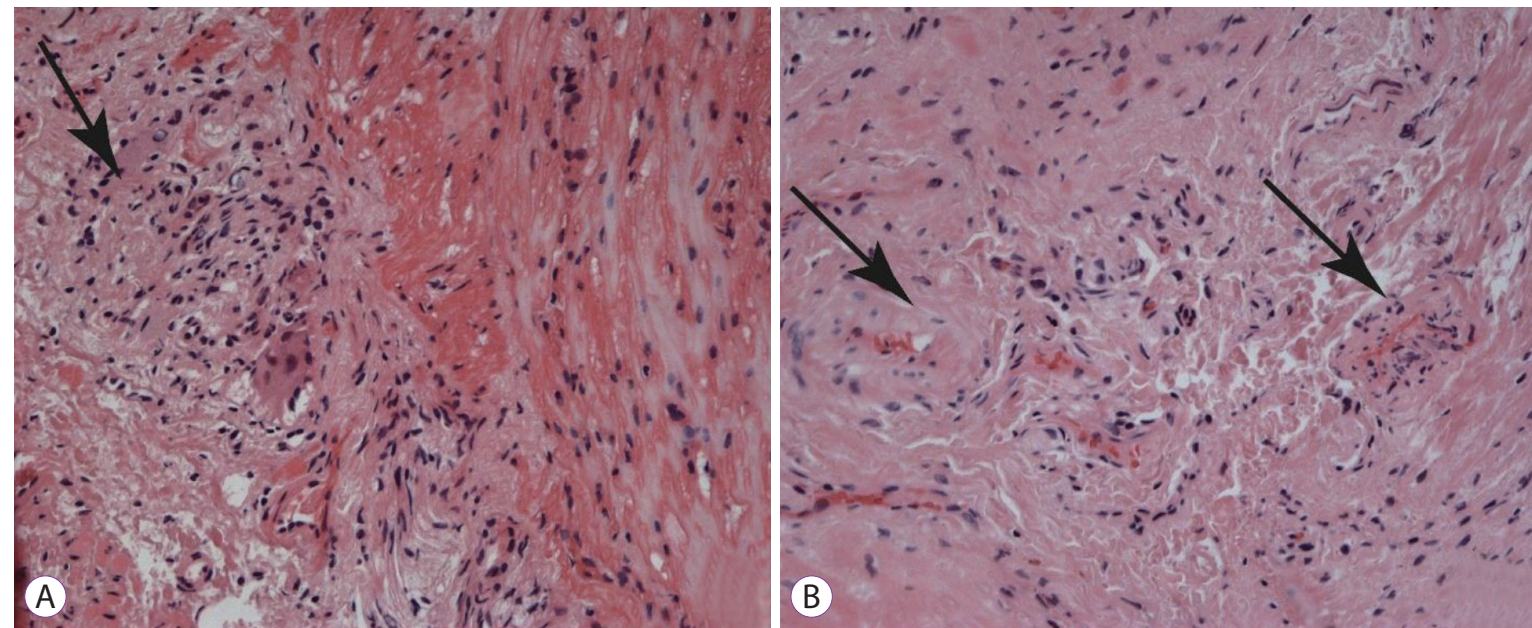

Fig. 5. Inflammatory infiltration composed predominantly of lymphocytes of the myenteric plexus. (A) Thickening of the vessel wall; (B) proliferative endarteritis with obliteration of the lumen of blood vessel (hematoxylin and eosin, $\times 200$ ). 
cosal incision was closed using endoscopic clips (Fig. 2).

Histological samples were stained with hematoxylin and eosin, picrofucsin (Van Gieson's technique), Congo red, and Masson's trichrome. Atrophic changes with diffuse sclerosis were revealed in the longitudinal and circular muscular layers of the esophagus (Fig. 3), as well as perivascular and perineural sclerosis (Fig. 4). In the myenteric plexus, inflammatory infiltration composed predominantly of lymphocytes was observed (Fig. 5A). Microcirculatory vessels were also implicated in the disease, appearing with thickening of the vessel wall, and proliferative endarteritis with obliteration of the lumen of the blood vessels (Fig. 5). Verified progression of the esophageal impairments and persisting skin changes resulted in the replacement of D-penicillamine with mycophenolate mofetil and the addition of iloprost for the treatment of Raynaud syndrome.

On postoperative day (POD) 1, the patient was administered with water. There was no fever and no complaints of pain. On POD 2, the patient was discharged for outpatient follow-up.

Three months later during a follow-up esophagoscopy, a $0.5 \mathrm{~cm}$ mucosal scar was observed in the location of the initial incision. No complaints from the patient were received.

\section{DISCUSSION}

Histological investigation of the fragment of the esophageal muscular layer, obtained by endoscopic tunneling biopsy, contributed not only to the verification of the esophageal involvement and myenteric plexus in SS but also to the severity of pathological changes. Based on that knowledge, we changed the treatment tactics: D-penicillamine was replaced by mycophenolate mofetil.

There are several techniques for the biopsy of the muscular layer of the gastrointestinal tract, but they have some limitations. In endoscopic no-hole full-thickness biopsy, there is no control specimen size, which is vital for the proper evaluation of the myenteric plexus. Myenteric plexus is not homogenous in the entire length of the esophagus and has ganglia at different distances from each other, thus the size of the biopsy material must be sufficient.,

According to the literature, endoscopic ultrasound-guided fine-needle aspiration is a safe and effective method, although there are some limitations: parts of the muscular layer are fragmented and it is difficult to correctly place the obtained specimens for a meaningful histological investigation. ${ }^{7}$

Considering the limitations of the techniques mentioned above, we propose the tunneling method as a safe method to perform biopsy with a direct visual control of the region of interest. Nowadays, many medical centers, such as ours, have sufficient experience in POEM and STER, making submucosal tunneling a mastered and routine procedure.

In conclusion, endoscopic tunneling biopsy is a safe and effective method for obtaining specimens of the esophageal muscular layer in patients with esophageal motility disorders to verify pathological changes in the esophageal musculature and myenteric plexus.

Conflicts of Interest

The authors have no financial conflicts of interest

\section{REFERENCES}

1. Kobara H, Mori H, Rafiq K, et al. Submucosal tunneling techniques: current perspectives. Clin Exp Gastroenterol 2014;7:67-74.

2. Knowles CH, De Giorgio R, Kapur RP, et al. Gastrointestinal neuromuscular pathology: guidelines for histological techniques and reporting on behalf of the Gastro 2009 International Working Group. Acta Neuropathol 2009;118:271-301.

3. Kahrilas PJ, Bredenoord AJ, Fox M, et al. The Chicago Classification of esophageal motility disorders, v3.0. Neurogastroenterol Motil 2015;27:160-174.

4. Gyawali CP, Kahrilas PJ, Savarino E, et al. Modern diagnosis of GERD: the Lyon Consensus. Gut 2018;67:1351-1362.

5. Rajan E, Gostout CJ, Lurken MS, et al. Endoscopic "no hole" full-thickness biopsy of the stomach to detect myenteric ganglia. Gastrointest Endosc 2008;68:301-307.

6. Rajan E, Gostout CJ, Wong Kee Song LM, et al. Innovative gastric endoscopic muscle biopsy to identify all cell types, including myenteric neurons and interstitial cells of Cajal in patients with idiopathic gastroparesis: a feasibility study (with video). Gastrointest Endosc 2016;84:512-517.

7. Othman MO, Davis B, Saroseik I, Torabi A, McCallum RW. EUS-guided FNA biopsy of the muscularis propria of the antrum in patients with gastroparesis is feasible and safe. Gastrointest Endosc 2016;83:327-333. 